\title{
MENGKAJI PENGGUNAAN SOFTWARE APPLE COLOR UNTUK COLOR GRADING SAAT PASCA PRODUKSI
}

\author{
Ahmad Faisal Choiril Anam Fathoni \\ Jurusan Desain Komunikasi Visual, Fakultas Komunikasi dan Multimedia, Bina Nusantara University \\ Jln. K.H. Syahdan No. 9, Palmerah, Jakarta Barat 11480 \\ anam.fathoni@binus.ac.id
}

\begin{abstract}
In post-production process, there is one process that is not as well known as the video editing process, the addition of animation, special effects enrichment, motion graphics or audio editing and audio mixing, an important process which is rarely realized called Color Correction or Color Grading. Various software have been made to handle this process, ranging from additional filters are already available for free in any editing software, to high-end devices worth billions of dollars dedicated for specifically conducting Color Correction. Apple Color is one of the software included in the purchase of Final Cut Studio package which also include Final Cut Pro for Video Editing, Soundtrack Pro for Sound Editing and Mixing, and Motion for compositing. Apple's Color is specially designed for color correction tasks after previously edited in Final Cut Pro. This paper is designed to introduce Apple's software as well as analyze the feasibility of Apple Color as a professional device in the world of production, especially post-production. Some professional color correction software will be compared briefly with Apple Color to get an objective conclusion.
\end{abstract}

Keywords: Apple color, color correction, color grading

\begin{abstract}
ABSTRAK
Dalam proses pasca produksi, ada salah satu proses yang tidak terlalu dikenal sebagaimana proses video editing, penambahan animasi, pengayaan special effects, motion graphics ataupun audio editing dan audio mixing, proses penting yang jarang disadari ini biasa disebut Color Correction atau Color Grading. Beragam perangkat lunak muncul untuk menangani proses ini, mulai dari filter tambahan yang sudah tersedia gratis dalam setiap perangkat lunak editing, sampai perangkat high-end berharga miliaran rupiah yang didedikasikan khusus untuk mengerjakan Color Correction saja. Apple Color merupakan salah satu software sertaan dalam paket pembelian Final Cut Studio yang tercakup di dalamnya Final Cut Pro untuk Video Editing, Soundtrack Pro untuk Sound Editing dan Mixing, Motion untuk Compositing, dan juga Apple Color yang khusus didisain untuk mengerjakan tugas-tugas Color Correction setelah diedit sebelumnya di Final Cut Pro. Tulisan ini dibuat untuk memperkenalkan sekaligus menganalisa kelayakan software Apple Color sebagai perangkat profesional dalam dunia produksi, khususnya pasca produksi. Beberapa software color correction profesional akan diperbandingkan sekilas dengan Apple Color untuk mendapatkan hasil kesimpulan yang obyektif.
\end{abstract}

Kata kunci: Apple color, koreksi warna, pemetaan warna 


\section{PENDAHULUAN}

Dalam dunia produksi yang terdiri dari pra produksi, produksi dan pasca produksi, perangkat lunak lebih banyak dijumpai pada proses pasca produksi. Mulai dari editing, animasi, motion graphics, dan masih banyak lagi. Salah satu proses yang jarang diulas ataupun diperhatikan adalah koreksi warna/color correction atau color grading, walaupun salah satu proses ini ikut menentukan sebuah karya masuk kategori amatir atau profesional, yang secara otomatis akan menaikkan nilai jual dari projek yang masuk kategori berbujet rendah sekalipun. Melihat kekuatan dari proses color grading ini dan kurangnya informasi tentang hal ini dalam dunia produksi, maka diperlukan tulisan-tulisan yang memperkaya pemahaman kita khususnya dalam proses pasca produksi yang membahas tentang proses, perangkat ataupun informasi lain yang berkaitan dengan hal tersebut.

Tulisan ini tidak akan secara spesifik membahas apa saja yang dilakukan dalam proses color correction, melainkan hanya secara sepintas menyentuh hal-hal penting yang merupakan inti dalam proses tersebut. Tujuan dari penulisan ini sendiri adalah untuk mengkaji kelayakan sebuah software color correction, dalam hal ini Apple Color untuk digunakan dalam proses pasca produksi. Hal ini diperlukan karena selain sangat jarang tulisan tentang software untuk color correction ini, pemahaman tentang pentingnya proses color grading ini juga belum memasyarakat di lingkungan kita, khususnya dunia akademis di Indonesia. Hal ini bisa terlihat dari sangat sulitnya mencari institusi pendidikan yang secara khusus mengajarkan tentang Apple Color maupun pelajaran tentang color correction untuk video digital.

\section{METODE PENELITIAN}

Penelitian dilakukan dengan melakukan kajian terhadap software Apple Color, mengeksplorasi beragam referensi yang menyangkut program ini, serta melihat kelebihan dan kekurangannya dibandingkan perangkat lunak lain yang memiliki fungsi yang sama.

\section{PEMBAHASAN}

\section{Proses Color Correction}

Color correction adalah suatu proses dalam pasca produksi yang berfungsi untuk menjaga kualitas dari hasil produksi melalui beberapa tahap, beberapa fungsi dari color correction adalah:

\section{Menjaga Materi untuk Memenuhi Standar Broadcast}

Apabila sebuah tayangan disiarkan ke televisi, maka stasiun televisi akan menetapkan persyaratan yang disebut dengan broadcast standard. Tujuannya adalah menjaga agar jangan sampai warna putih yang ada dalam materi yang akan ditayangkan terlalu menyilaukan, begitu pula dengan hitam juga tidak boleh terlampau gelap, karena selain gambar menjadi tidak layak untuk disiarkan, apabila sebuah video melampaui ambang batas nilai broadcast level, bisa memunculkan noise baik di gambar maupun di suara.

Tampak panah pada tampilan waveform (Gambar 1) memperlihatkan bagian tertinggi (yang mewakili putih) mencapai nilai 100, ini berarti gambar tersebut memenuhi broadcast level, bila nilainya lebih rendah, gambar nampak kurang terang, tapi jika nilainya lebih tinggi dari 100, maka akan menjadi terlalu putih, yang menyebabkan terlalu menyilaukan dan tidak masuk standar broadcast level. 


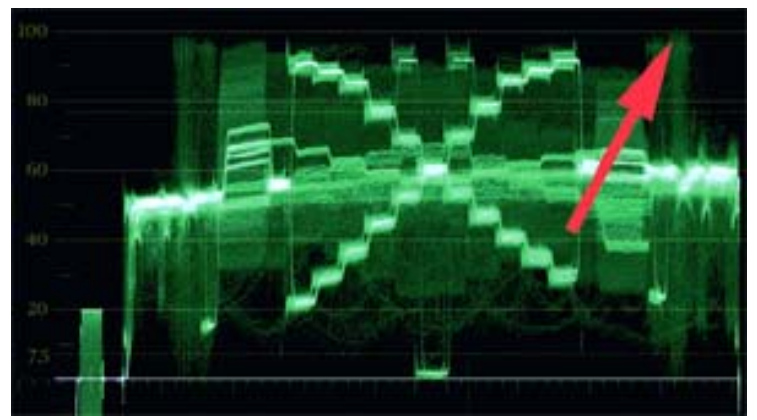

Gambar 1 Pengujian Broadcast Level dengan Tampilan Waveform.

\section{Menjaga Konsistensi Gelap Terang dalam Sebuah Video}

Tidak setiap proses produksi bisa dikontrol sepenuhnya. Ada kalanya walaupun lighting sudah diatur jarak dan kekuatannya, tapi bisa berubah karena kondisi shooting yang berjalan di luar perkiraan. Maka, kondisi shooting yang proper sekalipun bisa menghasilkan gambar yang tidak konsisten antara satu shot dengan shot yang lain. Di sinilah, colorist berperan menjaga konsistensi shot demi shot, menjaga setiap gambar agar tidak terlalu over atau under sehingga mata pemirsa tidak lelah. Pada proses editing dapat dilakukan koreksi luminance seperti pada gambar 2.

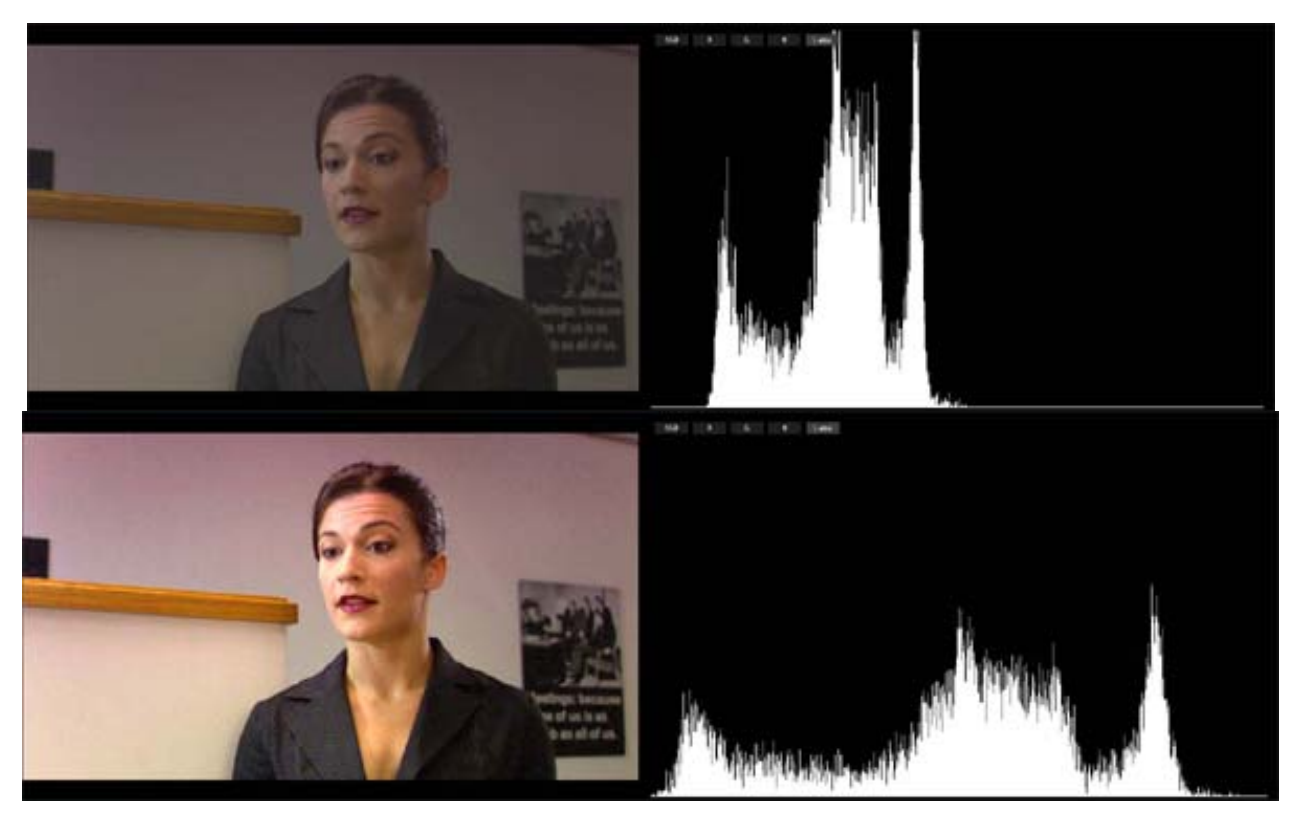

Gambar 2 Sebelum Koreksi Luminance (Atas) dan sesudah Koreksi Luminance (Bawah)

\section{Menjaga White Balance Agar Tetap Netral}

Proses shooting yang dikejar deadline, terlebih di banyak lokasi, seringkali menimbulkan permasalahan dengan melupakan setting white balance di kamera, oleh karena itu perbedaan color temperature antara lokasi indoor dengan outdoor menyebabkan beberapa shot menjadi muncul color cast-nya sehingga terlihat yellowish atau bluish. Salah satu peran color correction di sini adalah mengembalikan white balance, sehingga highlight akan kembali netral menjadi putih, dan shadow tetap menjadi hitam kembali. Pada proses editing dapat dilakukan koreksi white balance seperti pada gambar 3. 


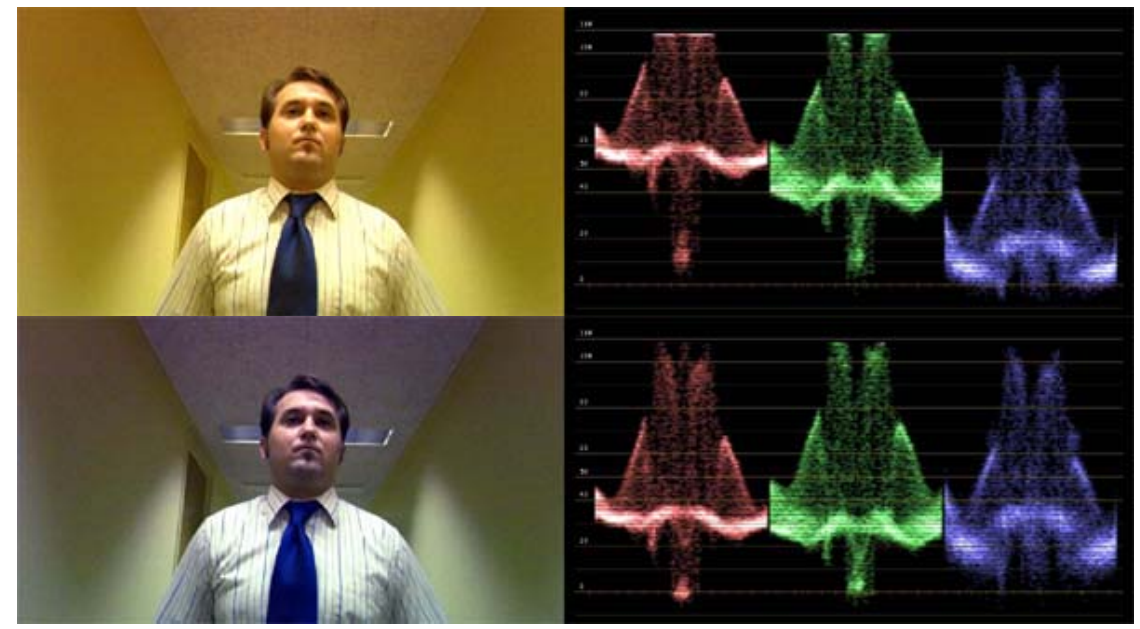

Gambar 3 Sebelum Koreksi White Balance (Atas) dan sesudah Koreksi White Balance (Bawah)

\section{Menonjolkan ataupun Mengurangi Warna atau Bagian Tertentu yang Diinginkan}

Dalam beberapa karya video, banyak kita jumpai beberapa shot yang diberi penekanan dengan menghilangkan warna sebagian objek, ataupun menonjolkan warna tertentu dengan menaikkan kecerahannya. Proses menonjolkan atau menghilangkan sebagian warna disebut dengan selective color correction (Gambar 4), sedangkan proses masking sebagian objek biasa disebut dengan spot correction (Gambar 5).

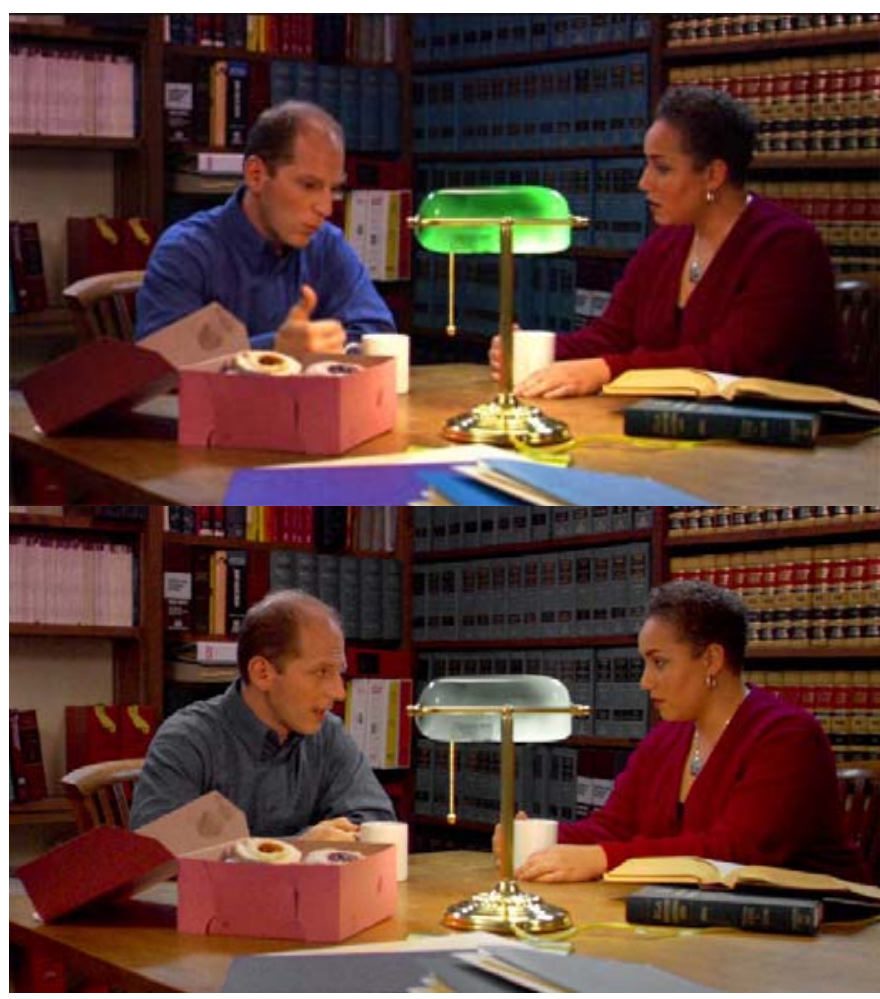

Gambar 4 Sebelum Selective color correction (atas) dan sesudah selective color correction (bawah) untuk menghilangkan warna yang mendominasi. 


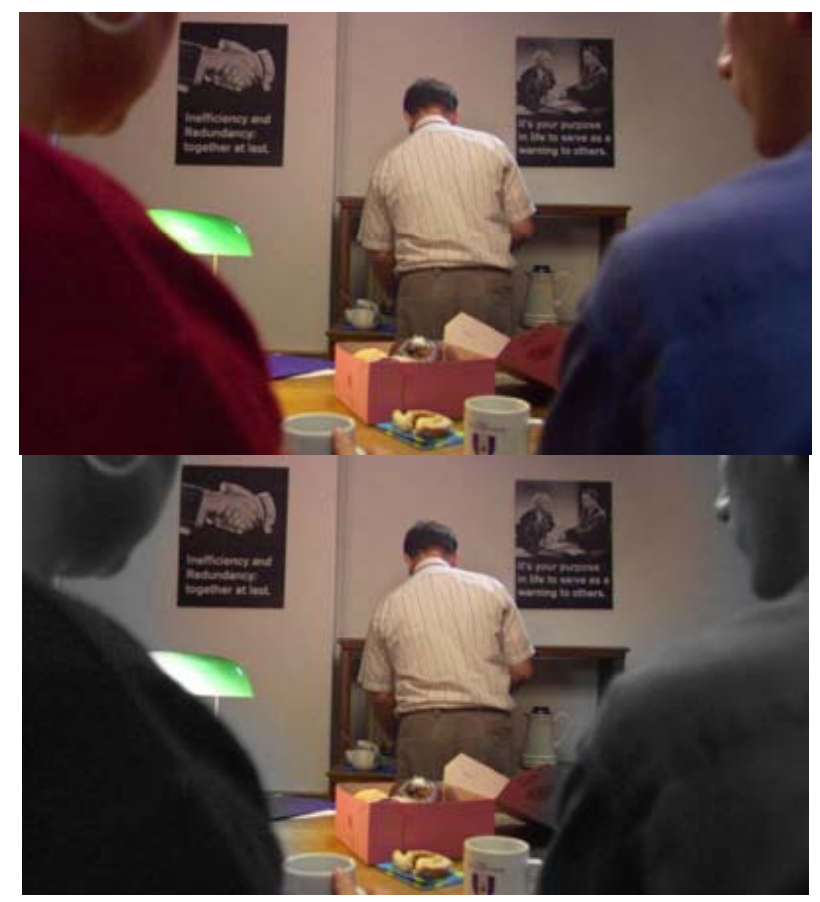

Gambar 5 Sebelum Spot Correction (Atas)

dan Sesudah Spot Correction (Bawah)

untuk Menghilangkan Warna di Sekelilingnya.

\section{Memberi Mood Baru dengan Efek Khusus}

Proses kreatif seorang colorist, terlihat di sini. Saat sutradara atau sinematografer menginginkan atmosfir yang berbeda, banyak sekali alternatif emosi yang bisa diwujudkan, mulai alam mimpi, ketakutan, alam surgawi hingga alam lukisan bisa dimunculkan dengan color correction.

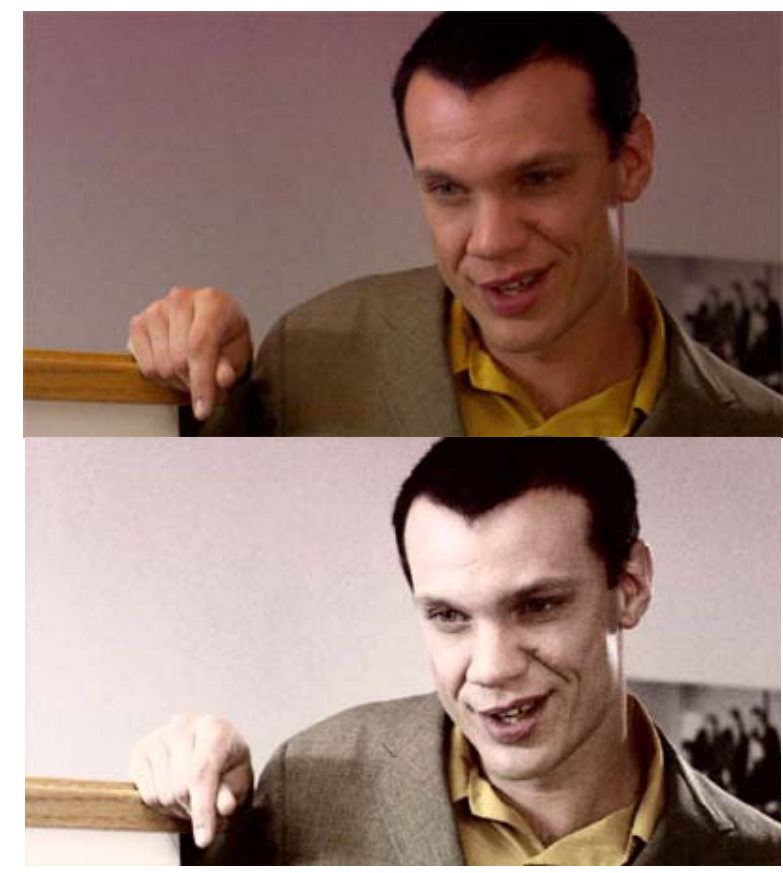

Gambar 5 Gambar Asli (Atas) dan Sesudah Pemberian Efek Bleach Bypas (Bawah) untuk Menambah Kesan Dramatis 


\section{Perangkat Lunak untuk Color Grading atau Color Correction}

Ada beragam software yang mampu melakukan koreksi warna untuk video. Ada yang merupakan fitur yang memang ditanamkan di dalam piranti lunak untuk penyuntingan video, ada juga yang merupakan program stand alone yang fungsinya hanya dispesifikkan untuk koreksi warna, bahkan ada juga yang sekedar plugin atau filter dari third party yang ditambahkan ke dalam software editing atau compositing. Perbedaan harga biasanya setara dengan kualitas yang diperoleh. Mulai dari plugin tambahan yang sifatnya gratis, hingga yang harganya mencapai miliaran dengan fungsi khusus untuk color correction semata.

Fokus kita kali ini adalah mengkaji Apple Color sebuah software color correction yang merupakan program sertaan yang diberikan apabila kita membeli Final Cut Studio. Pembelian Final Cut Studio seharga US\$ 999,- akan mendapatkan paket Editing Suite yang cukup menarik yang terdiri dari:

- Final Cut Studio (software untuk video editing)

- Color (software grading / color correction)

- Motion (software compositing)

- Soundtrack Pro (software audio editing)

- Compressor (software converter)

- DVD Studio Pro (software authoring)

\section{Apple Color}

Sebagai software sertaan, yang bukan merupakan program utama, Apple Color sering dipandang dengan sebelah mata. Terlebih oleh klien yang fanatik pada program-program grading dengan spesifikasi high end seperti Davinci, Lustre dan lain-lain. Apabila melihat dari segi harga, kita bisa melihat rentang yang cukup jauh dengan kompetitornya itu. Dengan harga US\$ 999 Color hanyalah satu dari enam program yang dibundel menjadi satu, sedangkan Davinci misalnya, adalah program stand alone (berdiri sendiri) khusus untuk grading, seharga mulai US\$ 995 - US\$ 19,995. Autodesk Lustre sendiri harganya bisa mencapai US\$ 170,000 di daerah North America.

Kali ini kita akan mencoba melihat interface dari Apple Color (Gambar 6). Pada sisi bagian atas, terlihat ada beberapa tab yang di dalam software ini dikenal dengan nama Room. Ada 8 room yang berbeda fungsinya, yang urutannya disesuaikan dengan workflow color correction yang benar, jadi proses dimulai dari Setup, diikuti Primary In hingga Render.

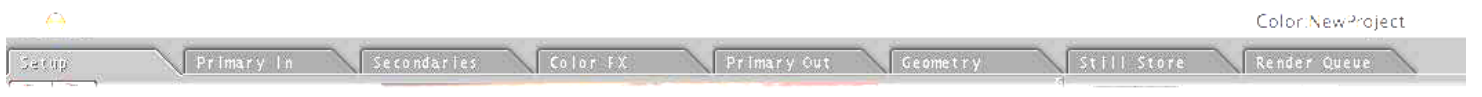

Gambar 6 Tab-tab dalam Interface Apple Color

Urutan sesuai dengan workflow yang proper ini menunjukkan kekuatan Apple Color sebagai software color grading yang serius, apalagi kalau kita hendak membandingkannya dengan perangkat color correction lain yang hanya merupakan plugin pada software video editing seperti 3 Way Color Corrector milik Final Cut Pro. Plugin-plugin sertaan Final Cut Pro, Vegas, atau Premiere menuntut colorist memahami proses yang benar terlebih dahulu, yang membuatnya mampu untuk menyusun plugin-plugin tersebut hingga menyamai prosedur yang benar dalam melakukan color correction. Hal ini merupakan kekuatan utama Apple Color yang mengukuhkannya sebagai software color correction yang profesional.

Bila kita masuk ke dalam Primary In, Secondaries dan Primary Out, di sisi kiri, terbagi menjadi 3 bagian, dimulai dari atas Video Preview, Waveform Scope, dan Vector Scope (Gambar 7). 


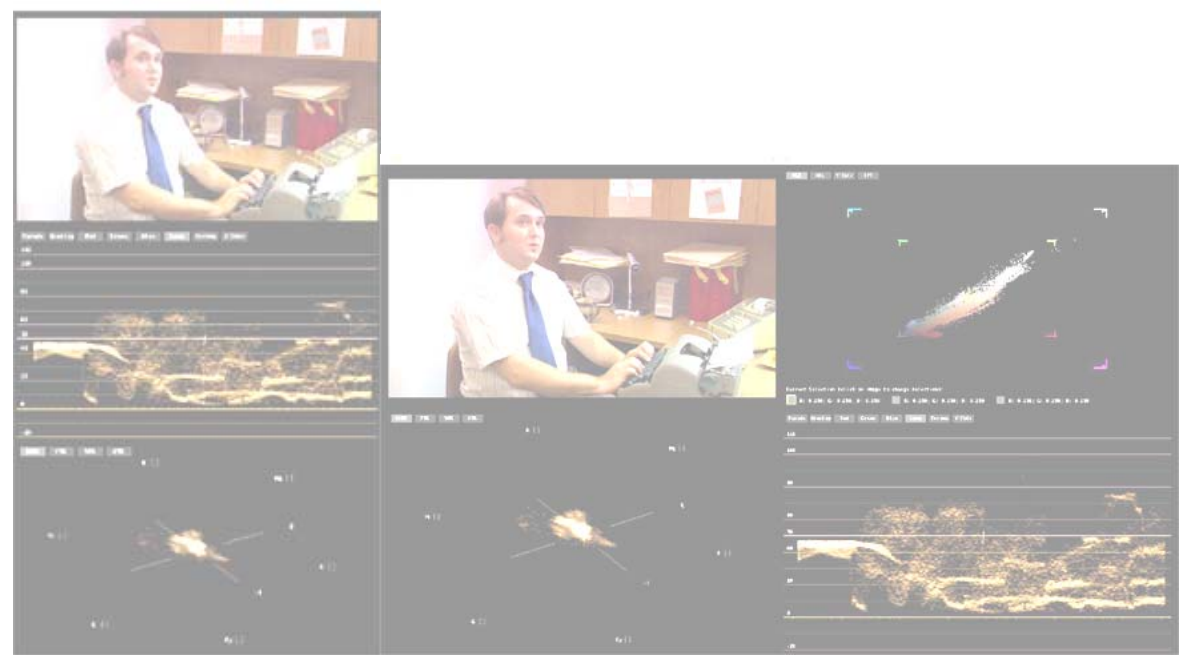

Gambar 7 Tampilan Layar Kerja Apple Color

Video preview berfungsi untuk menampilkan clip yang terseleksi, waveform scope di bawahnya merupakan alat monitor kadar gelap terang sekaligus melihat apakah sudah memenuhi broadcast legal atau tidak. Di bawahnya ada vector scope yang bisa kita pakai untuk memonitor warna dan menganalisa color cast. Apabila ditampilkan sebagai single display mode dalam satu monitor, tampilan menjadi terbagi 3 di sisi kiri, akan tetapi bila di-set dual display mode, maka akan menjadi 4 bagian yang akan muncul di second monitor, dan dapat diperbesar misalnya video previewnya menjadi full screen.

Hampir setiap software editing memiliki kedua scope ini, hanya saja Apple Color akan memunculkannya sebagai default, sedangkan software lain seperti Premiere ataupun Vegas tidak selalu tampil dan harus sesekali dimunculkan. Selain itu waveform Apple Color bila dibandingkan dengan waveform Apple Final Cut Pro (keduanya dari vendor yang sama, Apple) nampak bahwa di Apple Color jauh lebih detail, bahkan tingkatannya mendekati hardware scopes yang biasa dipasang di luar komputer editing. Untuk Davinci atau Avid DS, waveform tidak disertakan di dalam softwarenya, sehingga harus ditambahkan hardware scopes sebagai alat monitor. Hal ini merupakan kekuatan yang lain dari Apple Color, lebih praktis, efisien tapi tetap efektif dalam memonitor warna. Pada bagian tengah dalam Room Primary In, Secondaries, dan Primary Out terdapat 4 curves, yaitu Red, Green, Blue dan Luma Curve yang memungkinkan kontrol yang lebih luas selain dari 3 way color wheel di atasnya. Bahkan pada room secondaries terdapat curve yang spesifik untuk Hue Curve, Saturation Curve dan Luma Curve (Gambar 8).

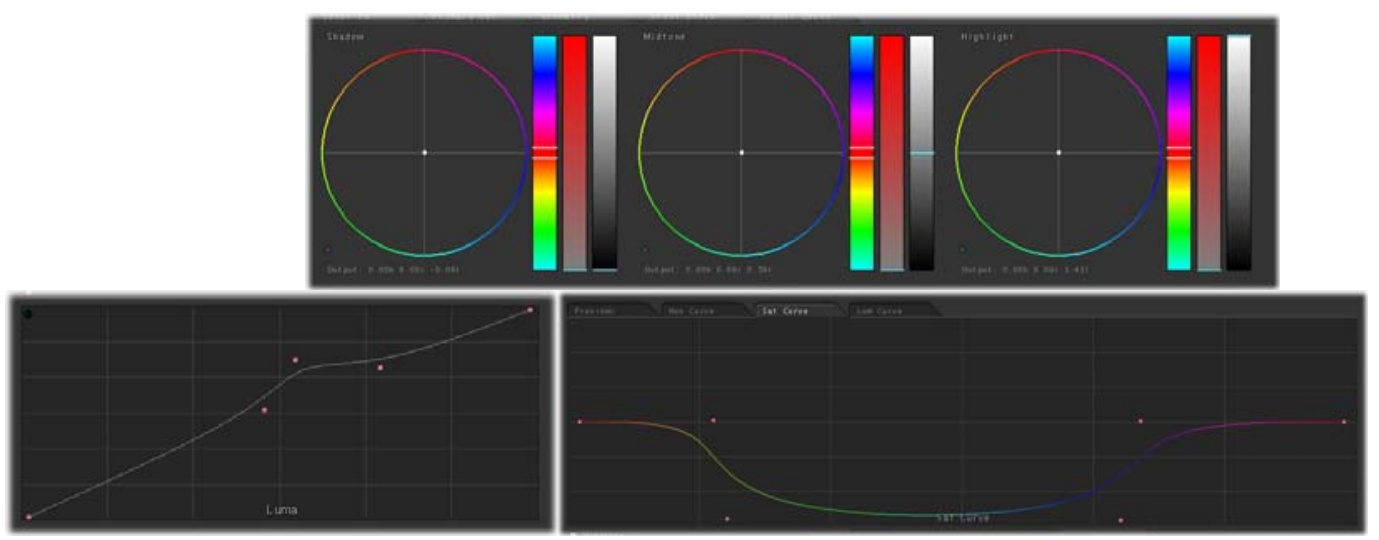

Gambar 8 Kontrol Warna dalam Interface Apple Color 
Final Cut Pro, juga memiliki 3 way color corrector, akan tetapi tidak adanya curve di Final Cut Pro, membuat adjustment di Apple Color tampak jauh lebih detail dan komprehensif.

Secondaries di Apple Color juga menampilkan kekuatannya di bandingkan Final Cut Pro.Untuk melakukan secondary correction, Final Cut Pro menggunakan limit effect, akan tetapi dengan tidak adanya tampilan matte (yang berupa tampilan hitam putih untuk menunjukkan bidang yang terpengaruh warna), membuat adjustment di Final Cut Pro lebih mengandalkan rasa dibandingkan teknis, karena harus menebak-nebak warna apa saja yang sudah terpengaruh. Sedangkan tampilan matte yang intuitif pada Apple Color, akan sangat memudahkan colorist dalam menentukan bagian-bagian atau warna yang akan diubah. Hal ini sudah pasti akan menghasilkan workflow yang lebih cepat dan efektif.

Hanya saja, walaupun secondaries di Apple Color merupakan kekuatan apabila dibandingkan dengan Final Cut Pro. Di sinilah kelemahan Apple Color apabila dibandingkan software grading yang masuk kelas high end. Apple Color memiliki 8 room dalam secondaries, dan masing-masing room bisa dipakai untuk memilih warna tertentu atau perlakuan tertentu seperti menambahkan vignette, hanya saja logika berpikir secondaries ini adalah serial dan bukan paralel. Dalam artian, perubahan pada room di depan akan mempengaruhi room di belakangnya. Sebagai contoh, apabila room 1 kita pakai untuk memilih warna merah, dan room 2 memilih warna hijau, sedangkan room 3 untuk warna orange, kemudian kita ubah lagi room 1 menjadi lebih cerah warnanya, maka warna orange di room 3 bisa saja ikut menjadi lebih cerah lagi, sehingga menuntut adjustment lebih lanjut untuk disesuaikan dengan seting awal.

Hal ini tidak berlaku pada Davinci ataupun Avid DS, yang menerapkan sistem paralel secondary correction, sehingga ketika satu warna diubah, warna lain tidak akan terpengaruh. Sehingga waktu kerja menjadi lebih singkat dan efisien. Kelemahan lain pada Apple Color secondaries adalah masking-nya (pembatas bidang yang akan diubah warnanya) yang terbatas sehingga apabila ada bagian yang bercampur antara satu warna dengan warna yang lain, akan mempersulit sistem kerja dan mengurangi kualitas hasilnya, dalam hal ini sulit bagi Apple Color mencapai tingkatan yang setara dengan software grading high end.

Software editing yang menggunakan beberapa color correction sebagai plugin seperti Final Cut Pro, Vegas dan Premiere, biasanya bila menginginkan lebih dari satu plugin akan disusun berurutan dari atas ke bawah dengan sistem layer. Apple Color menggunakan pendekatan yang jauh lebih advance sebagaimana software color correction high end, karena ada salah satu room utamanya yang terdapat di tab Color FX menekankan node base sebagai perangkat yang powerful dalam menyusun beragam efek secara tidak linear, beberapa bisa tersusun paralel bahkan bisa dihubungkan dengan cara yang tidak memungkinkan apabila dilakukan dengan sistem layer. Sistem node base (Gambar 9) ini adalah salah satu kekuatan terbesar Apple Color, karena dengan sistem ini membuat efek baru menjadi tidak terbatas.

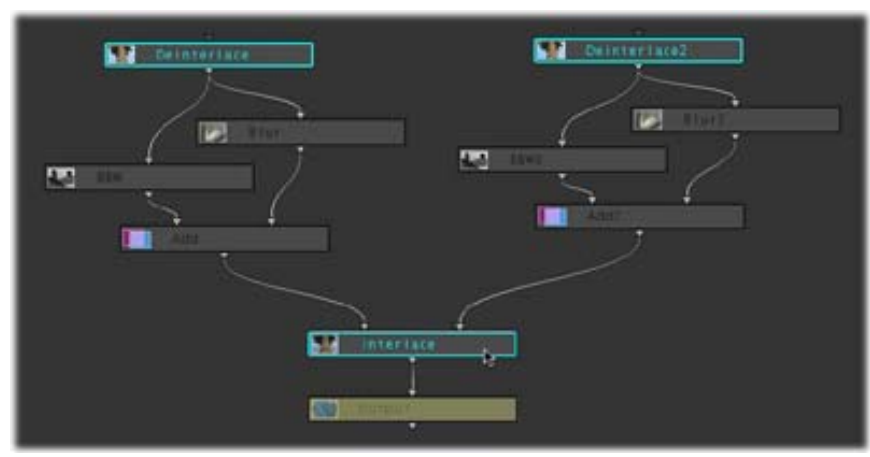

Gambar 9 Sistem Node Base pada Room Color FX 
Apple Color merupakan software pelengkap dari Final Cut Pro, walaupun Final Cut Pro memiliki perangkat color correction sendiri yang berupa plugin, akan tetapi kedalaman dan kekuatannya tidak bisa disamakan dengan Apple Color yang jauh lebih advanced. Proses grading di Apple Color biasa dimulai dari hasil editing di Final Cut Pro kemudian dikirim ke Apple Color dengan perintah Send To Color yang terdapat di menu utama Final Cut Pro.

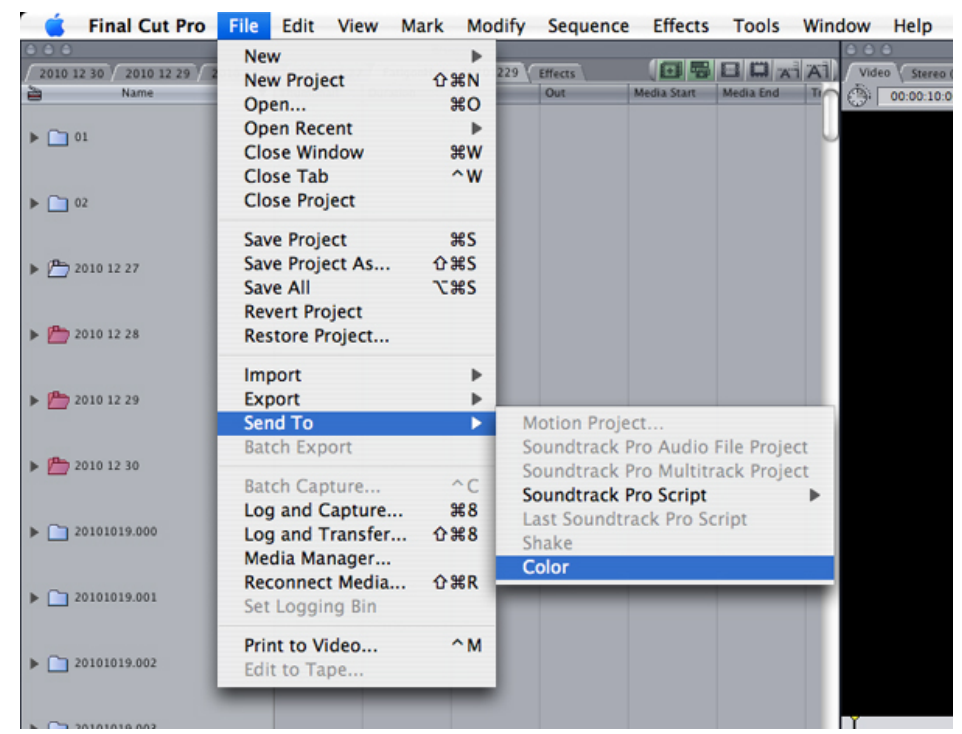

Gambar 10 Mengirimkan Video untuk Color Correction dari Final Cut Pro Ke Apple Color

Setelah dikirim ke Apple Color, maka proses grading sepenuhnya dilakukan di Color hingga selesai dan masuk ke room terakhir di Color yaitu Render Queue untuk di-finalize sebelum dikirim kembali ke Final Cut Pro. Begitu proses render selesai, hasil dari Apple Color dikirim kembali ke Final Cut Pro untuk proses pembuatan output berupa Betacam, DVD ataupun bentuk file, yang prosesnya juga melewati perintah Send To Final Cut yang terdapat pada menu utama Apple Color.

Proses yang membutuhkan waktu ini juga dilakukan apabila kita melakukan grading di software grading high end seperti Davinci atau Lustre. Itulah sebabnya tidak setiap color correction dilakukan di Apple Color, karena banyak sekali pekerjaan koreksi warna yang hanya membutuhkan plugin sederhana untuk color correction sebagaimana yang terdapat di Final Cut Pro. Koreksi sederhana ini akan jauh lebih cepat apabila kita eksekusi langsung di Final Cut dibandingkan harus melakukan Send To baik ke Apple Color maupun mengembalikannya ke Final Cut Pro.

\section{PENUTUP}

Dari tulisan di atas, dapat kita peroleh bahwa software Apple Color ini merupakan solusi yang tepat ketika kita menghadapi kondisi yang membutuhkan koreksi warna yang profesional dengan tingkat detail yang tinggi dengan bujet yang terbatas dan waktu yang tidak terlalu terburu-buru. Dalam projek yang membutuhkan kecepatan kerja yang sangat tinggi, Apple Color ini tidak dapat menandingi filter 3 way color correction, sebuah plugin standar Final Cut Pro yang memungkinkan koreksi cepat pada timeline tanpa harus keluar dari program Final Cut Pro itu sendiri. Sedangkan dari segi kualitas, spesifikasi yang dimiliki Apple Color, masuk kategori menengah, karena walaupun lebih baik dari filter standar namun masih belum bisa menyamai kekuatan perangkat-perangkat high-end yang memang didedikasikan khusus untuk Color Grading. 


\section{DAFTAR PUSTAKA}

Apple Inc. (2007). Color User Manual, Apple: Cupertino.

Hullfish, S. (2009). Color Correction for Video, Using Desktop Tools to Perfect Your Image, Burlington, Focal Press, ISBN 978-0-240-81078-2

Jones, S. B. (2003). Video Color Correction for Nonlinear Editors, Burlington, Focal Press, ISBN 0240-80515-1

Kennel, G. (2007). Color and Mastering for Digital Cinema, Burlington, Focal Press, ISBN 13: 978-0240-80874-1 